\title{
Attentional Factors Involved in Learning in the First Grade
}

\author{
Lucia Bigozzi, Amanda Grazi and Sara Pezzica
}

\author{
Department of Education and Psychology (SCIFOPSI), Division of Psychology, University of Florence, Italy
}

\begin{abstract}
In the school population, attentional problems are one of the most frequent causes of failure in learning; sometimes these take the form of a specific deficit and in other cases an attention disorder occurs in comorbidity with a learning disorder. It seems crucial to focus on what peculiar characteristics of attention are involved in basic learning in order to contribute to the diagnostic order and to arrange paths of development.

This research aims to verify the weight of the different components of attention involved in the outcomes of the first stages of learning.

A total of 69 children (34 males and 35 females, aged $6.4 \pm 1.1$ years and $7.3 \pm 1.2$ years respectively) in first grade, participated in the study. The results of the correlational analysis carried out show that there are specific significant relationships between the various components of attention and performance in reading, writing and calculation. In particular, visual attention appears to be the aspect most involved in the initial development of the learning of these three abilities.

Factorial analysis shows a single factor involved in the learning of reading, writing and calculation: "Rapid Visual Attention". The processes identified in the factor are: Selective Attention, Visual Selective Attention, Shifting Focus, Focused Attention, Planning and Inhibition. This factor is characterised by speed in Selective/Sustained Visual Attention and this explains the role of attention in success in reading, writing and calculation in the early stages of school learning.

The Rapid Visual Attention Factor contributes to rapidity in reading, speed in writing and numerical knowledge in first grade children, confirming the causal relationship between visual attention and initial learning in this age group. This "Rapid Visual Attention" Factor may be crucial in accounting for the comorbidity between Attention Deficit Hyperactivity Disorder and Learning Disabilities.
\end{abstract}

Keywords: Visual attention, literacy, numeracy, processing speed, attention deficit.

\section{INTRODUCTION}

Attention is a prerequisite for the development of academic learning [1]. The attentional skills involved in school activities are complex and require the activation of many processes [2]. For example, a student has to remember instructions, ignore stimuli from the classroom and pay attention to the task at the same time. The attentive functions involved in this activity are the ability to resist distraction [3], to inhibit automatic responses [4], to shift between different tasks [5], and to integrate these skills to solve complex problems [6]. Children demonstrate that they have knowledge of these attentional aspects to varying degrees [7]. Some children have problems both in attention and learning. So studying the relationship between attention and learning can provide important information both about the development of academic skills and about the understanding of the related disorders of attention and learning. In the school-aged population Learning Disabilities (LD) and Attention Deficit and Hyperactivity Disorder (ADHD) are very frequent. Learning problems occur in about $5 \%$ of school-aged children [8]. ADHD is one of the most common chronic childhood disorders. Current estimates indicate that approximately $3-10 \%$ of

*Address correspondence to this author at the Department of Education and Psychology (SCIFOPSI), Division of Psychology, University of Florence, Italy; Tel: +39 055 2755010; Fax: +39 055 2756134; E-mail: lucia.bigozzi@unifi.it

E-ISSN: 2292-2598/16 school-aged children can be diagnosed with ADHD [9]. This problem largely involves the families of these children [10,11]. ADHD and LD can co-occur frequently and there is a high mean comorbidity rate $(45.1 \%)$ [12]. LD percentages are highest for ADHD - combined type $(71 \%)$ and ADHD inattentive type (66\%) [13]. About $40 \%$ of children with ADHD also have a specific reading disorder $[14,15,16]$. Miller et al. [17] suggested that student attention is an important predictor of at-risk readers. Recently, Alloway et al. [18] studied the role of active attention in ADHD children's learning. The results provide evidence that the majority of children considered by their teachers to have attention problems, such as ADHD children, performed poorly in literacy and numeracy. Rabiner \& Coie [19] also reported that these children show lower reading skills in the early years of school. Many studies show that deficit in active attention is associated with poor academic results probably because this type of attention is the foundation of learning and is associated with learning disabilities regardless of the core deficit [20,21,22]. Pingault et al. [23] clearly indicated inattention as potentially the best predictor of later school failure in ADHD children. Genetic and environmental factors (family/school) may link ADHD and academic performance [24].

Peterson et al. [25] indicated that deficit in processing speed contributes to the overlap between 
reading/maths and attention. This overlap is interpreted within the context of the multiple deficit framework for neurodevelopmental [26] disorders in which a single deficit interacts with other neurocognitive risk and protective factors to determine the outcome in reading, calculation and attention. In this direction, also the processes of executive attention and working memory were studied to understand their role on the development of the subsequent learning. In fact, working memory capacity is associated with executive/active attention capabilities [27]: there is considerable interaction between these processes. The executive core of "working memory/active attention system" reflect a general capability to control attention and to maintain a limited amount of information in an active state, particularly in the presence of interference.

\section{Reading, Writing and Attention}

A recent study indicates that even in preschool children inattentive behaviours contribute individually, directly, and indirectly to the development of early literacy skills [28].

In normal development, decoding of written text in the early years of school requires visual perception skills and focused visuospatial attention [29]. The relationship between visual attention and learning in the early stages of reading acquisition has been confirmed by both studies of transparent orthographies such as French [30] and in opaque orthographies like English [31,32]. Deficits in visual search skills have also been found in Italian children with reading difficulties in first grade [33]. The reading process requires visual selective attention. This type of attention is focused spatially. Without this ability, the printed page would be a sea of visual clutter. For example, all scripts require selective attention to move serially in some ordered fashion (e.g., from left to right across a page and/or from top to bottom). In this direction, learning to read biases both the gradient of visual attention and scan patterns to align with the demands of the script being learned [34]. In the early stage of learning, an analysis of a text is similar to a visual search task: the child has to make a visual analysis of a specific target that is very different from all the symbols, which are letters [31,32]. Moreover, correct reading of a text and especially speed are associated with the ability of visual selective attention in the first two years of school [35]. Friedman et al. [36] proposed the concept of a visual orthographic module named visual analyser, which serves for analysis of the word specific domain.
Less studied is the link between attention and writing. Spelling plays a pivotal role in the acquisition of formal literacy [37]. Acquisition of writing is slower than reading, especially in the first year of learning [38]. The development of writing depends on an ability to maintain attention for prolonged periods of time. This kind of attention appears predictive of handwriting legibility in typically developing children [39]. Therefore, the writing process is more complex than reading and requires both phonological-visuospatial skills and visuomotor skills [40]. Verbal attentive elaboration and verbal working memory are very closely connected to spelling correctness [41]. In fact, the efficiency of active attention and working memory is linked to greater spelling correctness [42].

For ADHD children, a learning disability in written expression is twice as common (65\%) as a learning disability in reading or maths [43]. Studies on children with ADHD highlight the link between attention and visuomotor skills. These children have less ability in speed writing than children with Developmental Coordination Disorder [44]. So it seems that writing is greatly influenced by attentional difficulties, leading to difficulties also in spelling. In fact, it was found that behaviours of inattention are associated with homophone spelling errors (words that sound alike but are spelled differently) [45]. However, some studies also indicate a relationship between attention and nonhomophone errors. The errors are mainly accents and doublings [46]. The results confirmed that children with ADHD symptoms (between 8 and 11 years of age) have spelling difficulties, produce a higher percentage of errors compared to control group children, and that these difficulties are augmented under a higher load of active attentive elaboration of verbal information, especially for phonological errors.

\section{Calculation and Attention}

The association between ADHD and Maths Disability (MD) is estimated at around $18.1 \%$ [16]. Moreover, individuals with maths and attention disorders have more failures in academic achievement than children with ADHD alone. In particular, there is a stronger association between $\mathrm{MD}$ and inattention than between MD and hyperactivity/impulsivity [47]. Moreover, the deficits observed in MD concern temporal processing and attentive elaboration [48].

In their study, Ramussen \& Bisanz [49] showed that for preschool children the best and unique predictor of performance was visuospatial active attention. This finding is consistent with the view that pre-schoolers 
use a mental model for calculation that requires visuospatial active attention. In other studies, visuospatial attention and memory appear to be more important in pre-schoolers than in older children $[50,51]$. Visual spatial skills are also particularly involved in approximate arithmetic, rather than exact arithmetic [52]. Visual attention is also particularly involved in developmental dyscalculia [50].

Moreover, phonological attentive elaboration is also involved in both multiplication and recovery of arithmetic facts [53,54].

Bull \& Scerif [55] suggested that deficits in inhibition process and poor active attentional elaboration characterise children with difficulties in mathematics. Interestingly, recent data suggest an association between maths and ability to ignore irrelevant information during memory tasks. Bull et al. [56] identified a relationship between maths skills and processes of inhibition of automatic responses and cognitive flexibility in typically developing children. Steele et al. [57] found that pre-schoolers' performance in attentional "go-no go" tasks and visual search correlate with future maths skills measured in first grade. Children who have a low performance in mathematics also have difficulty in inhibiting the strategy learned and so use new strategies [58].

\section{Aims}

There are few studies that have investigated reading, arithmetic and attention simultaneously. Moreover, the findings on attentional constructs are controversial in the developmental period. Klenberg et al. [3] found that performance reached a plateau at different time points for inhibitory processes, sustained, selective and executive attention tasks in 3- to 12-yearolds. Manly et al. [58] also suggested a three-factor model of sustained and selective attention and a higher-level "executive" attention, even in 6- to 16-yearold children. In younger children (under 4 years) [59] a two-factor model seemed to best capture attentional constructs. A two-factor model in younger children (3to 6-year-olds) was also confirmed by Steele et al. [57]. In this case distinct trajectories across attention measures revealed the emergence of executive and sustained-selective processes.

We addressed three specific questions in this study.

1) We investigated what kind of attention is involved in early academic learning: reading, writing and arithmetic.
On the basis of the literature $[35,51]$ the assumption is that there is a greater involvement of visuospatial skills in early learning.

Few studies have investigated the relationship between attentional abilities and writing processes, so we wanted to see whether visuospatial attention may also be involved in early learning of writing.

2) We evaluated what is the factor structure of attention in first grade children.

3) We evaluated whether there is a causal link between reading, writing and calculation and attention factor founded in the initial acquisition of learning.

\section{METHOD}

\section{Participants}

A total of 69 children (34 males, mean age equal to $6.4 \pm 1.1$ years; 35 females mean age equal to $7.3 \pm 1.2$ years) participated in the study.

The children all attended the same institute including a school on the outskirts of a large city in the centre of Italy. We excluded all students with a disability and/or developmental disorder (as diagnosed by the national health system). The tests were administered at a time agreed upon with the school and with due adherence to the requirements of privacy and informed consent required by Italian law (Legislative Decree 196/2003). Regarding the ethical standards for research, the study referred to the latest version of the Declaration of Helsinki by the World Medical Association [60]. The study was approved by the Departmental Ethics Committee, Dipartimento di Psicologia, Università degli Studi di Firenze, Italy.

\section{Procedures}

The parents agreed with written consent to their children taking part in the project. The children themselves were informed of the purposes of the research before the start of testing. Parents were able to take their children out of the study at any time. The evaluations were given by specialists in Child Psychology. Each child participated in the administration of collective testing in 2 meetings of one hour and performed individual tests in a meeting lasting about 40 minutes. The set of tests included dictation, speed writing, arithmetic and some tests of attention. For the attention test with time limits, the child had to 
raise his or her hand at the end of his/her performance and time allocated for writing. The individual tests were conducted in a small group in order not to isolate children and so that they did not perceive the test as an exam. Each child performed the tests individually where three other children were working with other operators. The room was separated from the classroom and spacious enough to include three different areas. A pleasant cooperation was established with all the pupils. The children were informed that the tests were not carried out as an examination but due to a need to understand how children learn to read and do arithmetic. The tests were administered in the period from May to June; at this time of the school year, children are expected to have consolidated their learning.

\section{MATERIALS}

\section{Tests of School Performance}

Reading task-speed and accuracy of text reading were assessed using the MT battery [61]. This battery is the most commonly used Italian instrument to measure passage reading speed and accuracy. The child has to read a text titled "La storia di Babbo Natale." It comprises different passages for each grade level with increasing number of syllables and complexity of text. The internal reliability coefficient is $=.90$.

Writing task- The task was derived from the battery for the assessment of writing skills in children between 7 and 13 (Batteria per la valutazione delle competenze ortografiche nella scuola dell'obbligo), which is the standardised complete writing battery available in Italy [62]. The child has to write a text that is dictated. The specific dictation is titled "La bicicletta del papà". Spelling competence was calculated based on the number of phonological and non-phonological errors per total number of written words $[63,64,65]$. Children may misspell by writing graphemes representing the wrong phonemes or in the wrong order, or by leaving some out. These errors misrepresent the target word and might be called non-homophone errors. But where phonemes have more than one spelling, the child may also choose the wrong grapheme; these errors will preserve the pronunciation of the target word and may be called homophone errors. The internal reliability coefficient for phonological is $=.78$ and for nonphonological is $=.59$.

Speed writing task-This task was in the Italian 'Battery for the assessment of writing skills of children from 7 to 13 years old' [66]. The child has to write the syllable "le" repeatedly and connect the graphemes. The score of the test is given by the number of couples "le" correct. The internal reliability coefficient is $=.83$.

Battery of Calculation Ability-To evaluate calculation ability, subtests from the standardised Battery of Calculation Ability [67] were used. We used some subtests:

- Mental calculation: this subtest provides the scoring of number or errors and rapidity in oral calculation,

- Written calculation: this subtest provides the scoring of accuracy in written calculation,

- Numerical knowledge: composed of perception of numerosity, transformation into number, sorting numbers.

The internal reliability coefficient is $=.74$ for competence in calculation and for numerical knowledge $=.55$.

\section{Tests of Attention}

\section{Cognitive Assessment System (CAS)}

The CAS is a battery for multidimensional measure of cognitive processing based on the PASS theory of intelligence [68]. A standard score is provided for each cognitive process (Planning, Attention, Simultaneous and Successive). We used only Planning and Attention scores. For the Attention score we used:

- Number detection (functions involved: Selective Attention, Shifting Focus). Children are instructed to find and underline the target numbers (as reported in the example) among many distractors. Accuracy and speed are recorded for each item.

- Receptive attention (Focused Attention). Each child has to find and underline couples of figures. The child has to underline the couples on the basis of the graphic similarity or category (name). There are also some distractors (couples with different figures). Accuracy and speed are recorded for each item.

- Expressive attention (inhibit automatic responses, interference control). The child has to identify large or small animals. The real dimensions of the animals do not correspond to 
the figures. Accuracy and speed are recorded for each item.

For the Planning score we used:

- $\quad$ Matching numbers (functions involved: Planning, Selective Attention). The task requires the identification of identical numbers as quickly as possible. The time needed to complete the task is recorded along with the number of correct answers.

- $\quad$ Planned codes (Planning, Inhibition). The task includes codes arranged in seven rows and eight columns. Each child has to complete empty cells with the correct corresponding code, based on the example provided. Accuracy and speed are recorded for each item.

The internal reliability coefficients are for Planning $=.88$ and for Attention $=.88$. The progression of scores across ages is measured.

\section{Visuospatial Working Memory}

We used visuospatial working memory tasks requiring different levels of control. These tests were used because they permit an assessment of level of attentional control (i.e. low attentional control/passive tasks or high attentional control/active tasks). The tests require different processing levels of the material to be remembered with greater involvement of the central executive system tasks at low and high level of control.

The first three tests were derived from the battery for the assessment of visuospatial working memory in children between 4 and 6 years [69] (Prove per la valutazione della working memory visuospaziale).

The tests administered are the following.

Test 1 (low control) Memory Positions. The task consists of the storage of the position of green boxes on a checkerboard made up of $2 \times 2,3 \times$ 3 or $4 \times 4$ squares. The test has five levels of increasing difficulty determined by the number the positions to be stored ( 2 or 3 ) and by the size of the board $(2 \times 2$ in the first level, $3 \times 3$ in the second and in the third and $4 \times 4$ in the last two). Each level of difficulty is made up of two series of items.

Test 2 (medium control) Selective Recall. The test consists of only recalling the first box of one or more routes taken by one or two frogs on a checkerboard $4 \times 4$.

- $\quad$ Test 3 (high control) Double Task. In addition to storing the first box of a route made by a frog on a board $4 \times 4$, as in the previous test, the child is asked to perform concurrent task of beating his hand on the table when the frog jumps on a box of red colour.

The score of "Paths" is achieved through administration of all three tests.

The internal reliability coefficients are: Memory Positions $=.69$, Selective Recall $=.69$, Double Task $=.80$.

The Corsi block-tapping task is a widely used test to assess visuospatial working memory. The test is administered using nine square blocks positioned on a wooden board. The child has to memorize a series of positions and then remember them backward. In this study we used backward conditions with an Italian version of the Corsi task $[70,71]$. The internal reliability coefficient is $=.74$.

\section{Intelligence Quotient}

The following tests were used as control variables. We administered two subtests of the Wechsler Intelligence Scale (WISC-III): Similarities and Block Design $[72,73]$. Internal reliability for subtests ranged from .79 to .90 . The administration of the test to estimate the IQ is considered a reasonable strategy in research studies where intellectual functioning is not the main objective of the assessment [74]. The two selected tests Similarities and Block Design are representative of verbal reasoning ability and performance respectively.

\section{RESULTS}

In a first step, the descriptive statistics of the metric variables (mean, standard deviation, skewness and kurtosis coefficients, minimum and maximum values) were calculated.

The normality assumptions for the emergent literacy variables were verified. For all the variables that were not normally distributed, increasing monotonic transformations were applied.

In a second step, Pearson's partial correlation coefficients were performed between measures of 
attention, ability in verbal/visuospatial reasoning, memory and scholastic performance (in reading, writing and calculation); the intelligence measures (Cubes and Similarities of WISC Test) were considered, in the Pearson's partial correlations, as control variables.

At a later time, the total sample was randomly split into two sub-groups and, on the first sub-group, an Exploratory Factor Analysis (EFA) was carried out on the performances in the attention tasks, to identify their factorial latent structure. The aim of the factorial analysis was to obtain a more reliable measure of the "attention construct" compared to that obtained by considering each "attention subtest". Kaiser-MeyerOlkin (KMO) and Bartlett's sphericity test were calculated, to check that the correlation matrix satisfied the factorability assumptions. Regarding the EFA, Principal Axis Factoring (PAF) was used as the extraction method, and a Promax procedure was followed as the rotation criterion. Unlike the Principal Components Analysis (PCA), PAF is a form of factor analysis that brings together the least number of factors obtained from the common variance into a set of variables, while the most common PCA extracts factors from both the common and unique variances of a specific group of variables. The internal reliability for each factor was estimated with Cronbach's Alpha coefficient. The tests included in the factor analysis were selected from theoretical premises from the most recent studies on this topic $[57,59]$.

Then, to evaluate the model's goodness of fit, through a CFA, on the second sub-sample several indexes were measured: together with the chi-square test, which has the limit of being sensitive to sample size, the CFI (Comparative Fit Index) and TLI (Tucker Lewis Index) were considered. Usually values higher than .90 are considered satisfactory $[75,76]$. Moreover, the RMSEA (Root Mean Square Error of Approximation) and SRMR (Standardised Root Mean Square Residual) were calculated; values lower than .08 show satisfactory adequacy [77].

Finally, several multiple regression analyses (one for each performance variable) were carried out considering, as set of independent variables, the attention factor (indicated by EFA and confirmed by CFA), measures of verbal/visuospatial reasoning and memory ability.

\section{Descriptive Statistics and Correlations between Attention and Learning}

In the tables below the descriptive statistics of all the metric variables measured on the total sample are reported (Tables $\mathbf{1}$ and $\mathbf{2}$ ).

In Table 3 partial correlations between learning measures, measures of attention and working memory are reported, computed considering the scores in the intelligence measures as control variables.

The reading performances were significantly correlated with visuospatial selective attention (Number detection). Children who had obtained a better score in this attentional process had higher rapidity in reading $(r$ $=.31, p<0.05)$ and made fewer mistakes $(r=-.24, p<$ $0.05)$.

Non-homophone errors do not show a significant correlation, while Homophone ones were correlated inversely with visuospatial abilities (Paths, $r=-.24, p<$ .05). Speed writing (fluency) in this age group is associated with attentional skills and in particular with those of visual selection (Number detection) and

Table 1: APA Norms Statistical Description of all the Learning Measures: Number of Participants, Minimum and Maximum Values, Mean, Standard Deviation, Skewness and Kurtosis Coefficients

\begin{tabular}{|c|c|c|c|c|c|c|c|c|}
\hline & Measure & $\mathbf{N}$ & Min & Max & $\mathbf{M}$ & SD & Skewness & Kurtosis \\
\hline \multirow{2}{*}{ Reading } & Errors & 57 & 0 & 22 & 7.16 & 5.05 & .71 & .12 \\
\hline & Rapidity & 57 & .07 & 3.15 & 1.13 & .66 & 1.01 & .90 \\
\hline \multirow{3}{*}{ Writing } & Non-homophone errors & 54 & 0 & 22 & 8.13 & 5.38 & .49 & -.06 \\
\hline & Homophone errors & 55 & 0 & 12 & 3.69 & 2.17 & 1.05 & 2.7 \\
\hline & Writing rapidity: Number of graphemes & 44 & 2 & 40 & 16.77 & 1.66 & .44 & -.85 \\
\hline \multirow{4}{*}{ Maths } & Errors (oral calculation) & 58 & 0 & 18 & 3.17 & 3.07 & 2.20 & 8.23 \\
\hline & Time (oral calculation) & 56 & 17 & 270 & 82.45 & 46.18 & 1.66 & 4.46 \\
\hline & Written calculation & 60 & 0 & 4 & 3.03 & 1.10 & -.92 & .13 \\
\hline & Numerical knowledge & 58 & 0 & 16 & 13.24 & 2.83 & -2.18 & 7.41 \\
\hline
\end{tabular}


Table 2: APA Norms Statistical Description of all the Attention, Visuo-Spatial Working Memory and Control Measures: Number of Participants, Minimum and Maximum Values, Mean, Standard Deviation, Skewness and Kurtosis Coefficients

\begin{tabular}{|c|c|c|c|c|c|c|c|c|}
\hline & Measure & $\mathbf{N}$ & Min & Max & $\mathbf{M}$ & SD & Skewness & Kurtosis \\
\hline \multirow{3}{*}{$\begin{array}{l}\text { Measures of } \\
\text { attention }\end{array}$} & Number recognition & 59 & 2 & 17 & 11.59 & 2.86 & -.71 & 1.32 \\
\hline & Expressive attention & 56 & 5 & 16 & 9.79 & 2.87 & .29 & -.94 \\
\hline & Planned codes & 60 & 4 & 17 & 1.3 & 2.66 & .08 & -.35 \\
\hline \multirow{2}{*}{$\begin{array}{c}\text { Visuo-spatial } \\
\text { working } \\
\text { memory }\end{array}$} & Paths & 57 & 2 & 24 & 15.81 & 4.84 & -.51 & .04 \\
\hline & Corsi's Test backward & 51 & 2 & 6 & 3.29 & .87 & .48 & .60 \\
\hline \multirow{2}{*}{$\begin{array}{l}\text { Control } \\
\text { measures }\end{array}$} & Cubes (Wisc) & 50 & 2 & 18 & 11.54 & 2.97 & -.54 & 1.60 \\
\hline & Similarities (Wisc) & 54 & 4 & 19 & 12.13 & 3.18 & -.13 & -.23 \\
\hline
\end{tabular}

Table 3: Correlation between Learning Measures, Measures of Attention, Visuo-Spatial Working Memory

\begin{tabular}{|c|c|c|c|c|c|c|c|}
\hline Measure & $\begin{array}{l}\text { Number } \\
\text { detection }\end{array}$ & $\begin{array}{l}\text { Receptive } \\
\text { attention }\end{array}$ & $\begin{array}{l}\text { Expressive } \\
\text { attention }\end{array}$ & $\begin{array}{l}\text { Matching } \\
\text { numbers }\end{array}$ & $\begin{array}{l}\text { Planned } \\
\text { codes }\end{array}$ & Paths & $\begin{array}{l}\text { Corsi Test } \\
\text { backwards }\end{array}$ \\
\hline \multicolumn{8}{|l|}{ READING } \\
\hline Speed & $0.31^{*}$ & 0.09 & -0.11 & 0.14 & 0.19 & 0.13 & 0.07 \\
\hline \multicolumn{8}{|l|}{ WRITING } \\
\hline Homophone errors & -0.14 & 0.01 & 0.21 & -0.13 & -0.04 & -0.24 * & -0.21 \\
\hline $\begin{array}{l}\text { Speed writing (numbers of } \\
\text { graphemes) }\end{array}$ & $0.33^{* *}$ & 0.18 & 0.01 & $0.26^{*}$ & 0.01 & 0.22 & 0.00 \\
\hline \multicolumn{8}{|l|}{ CALCULATION } \\
\hline Numerical knowledge & $0.42^{* *}$ & $0.27^{*}$ & -0.01 & 0.22 & $0.32^{\star \star}$ & 0.20 & 0.05 \\
\hline
\end{tabular}

Note. Cognitive functions involved in each test; Number detection=Visual Selective Attention, Shifting Focus; Receptive attention= Focused Attention; Expressive attention=Inhibit automatic responses, interference control; Planned codes=Planning, Inhibition; Matching numbers=Planning, Selective Attention. ${ }^{*} \mathrm{p}<.05 ;{ }^{* *} \mathrm{p}<.01$.

strategic planning (Matching numbers) (respectively: $r$ $=.33, \mathrm{p}<.01 ; \mathrm{r}=.26, \mathrm{p}<.05)$.

Oral calculation errors were associated with visuospatial working memory/active attentional system (Paths and Corsi Backward) (respectively: $r=-.25, p<$ .05 and $r=-.27, p<.05)$. Calculating rapidity correlates positively $(r=.31, p<.05)$. with the ability to plan (Planned codes), while the correct execution of written operations is associated with the ability to control interference (Expressive attention, $r=.24, p<.05$ ). Numerical knowledge includes ability to recognise and order larger and smaller numbers and recognise the positional value of digits. This competence is related to variables of planning (Matching numbers) $(r=.32, p<$ .01 ), selective visuospatial attention (Number detection) $(r=.42, p<.01)$ and focused attention (Receptive attention) $(r=.27, p<.05)$ (Table 3).

\section{Latent Factorial Modelling of Attention: EFA}

An EFA on the performances in the participants attentional tests was carried out on the first sub-sample of participants and, coherently with Steele et al. [54] for 
children of 3-6 years old, we had hypothesised a bifactorial model: a first factor of selective attention and a second factor of executive attention with high attentional load. The KMO was .72 and Bartlett's Sphericity test resulted statistically significant $\left[\mathrm{X}^{2}(21)=\right.$ $106.25, p<.01$ ], showing a good factorability of correlation matrix. Analysis of the scree plot showed the presence of two factors with an explained variance of $38.32 \%$ of total variance.

After the exclusion of Corsi's Test (backward) and of Expressive attention measure, because communality was too low, the KMO amounted to .75 and Bartlett's test resulted significant $\left(\mathrm{X}^{2}(6)=70.37, \mathrm{p}<.001\right)$. Scree Plot showed a unifactorial model which explained 46.75 $\%$ of the total variance in the correlation matrix. The tests within the factor were all found to have loadings greater than .30, and are reported below (Table 4).

Table 4: Exploratory Factor Analysis (EFA) of Attentive Measures Factorial Loadings of the Unifactorial Model

\begin{tabular}{|l|c|}
\hline \multicolumn{1}{|c|}{ Measure } & Factorial loadings \\
\hline \hline 1. Number detection & .53 \\
\hline 2. Receptive Attention & .60 \\
\hline 3. Matching numbers & .71 \\
\hline 4. Planned codes & .57 \\
\hline
\end{tabular}

\section{Latent Factorial Modelling of Attention: CFA}

Regarding the CFA of the model, carried out on the second sub-sample of participants, the analysis showed the same latent factorial structure pointed out by the EFA. $x^{2}$ resulted not significant $\left(X^{2}(2)=1.25, p=\right.$ n.s.), indicating an excellent fit of the model to the observed data. Other fit coefficients, i.e. CFI and TLI assumed values above .90 (.97 and .96 , respectively). The RMSEA and SRMR coefficients, i.e. decremental measures of goodness of fit, pointed out lower scores than the critical value of .08 (.01 and .03, respectively). The loadings of the factors obtained through the confirmatory analysis are all greater than .30 (Table 5).

Table 5: Confirmatory Factor Analysis (CFA) of Attentive Measures in the First Class: Factorial Loadings of the Unifactorial Model

\begin{tabular}{|l|c|}
\hline \multicolumn{1}{|c|}{ Measure } & Factorial loadings \\
\hline \hline 1. Number detection & .90 \\
\hline 2. Receptive Attention & .58 \\
\hline 3. Matching numbers & .78 \\
\hline 4. Planned codes & .68 \\
\hline
\end{tabular}

Does the Attention Construct Predict Scholastic Performances? Multiple Regression Analysis

Concerning errors in reading, only Similarities (WISC) turned out to negatively predict the errors made by the participants ( $\mathrm{t}(62)=-3.52, \mathrm{p}<.001, \eta^{2}=.17$ ), while any attention and visuo-spatial working memory variables turned out to be statistical significant predictors (Table 6). Regarding rapidity in reading, the Attention factor turned out to be a significant regressor by a directly proportional relationship $(\mathrm{t}(62)=2.17, \mathrm{p}<$ $.05, \eta^{2}=.07$ ), together with the Similarities (WISC) test (t $\left.(62)=3.71, p<.001, \eta^{2}=.18\right)$; so, the higher the Attention factor score was, the higher the rapidity shown in reading was (Table 7 ).

As regards the homophone and non-homophone errors in writing, no predictor turned out as statistically significant, while for rapidity in writing the only regressor that resulted significant, by a directly proportional relationship, was the Attention factor ( $t$ $\left.(62)=2.27, p<.05, \eta^{2}=.08\right)$; the higher the Attention factor score was, the higher the rapidity shown in writing was (Table 8).

Finally, regarding the prediction of the measures of mathematical performance, the errors in oral calculation turned out as predicted by Corsi's Test Backward ( $\left.\mathrm{t}(62)=-1.01, \mathrm{p}<.05, \eta^{2}=.08\right)$ and by Similarities (WISC) (t $(62)=-3.60, p<.001, \eta^{2}=.17$ ); both the regressors were associated with the criterion variable by a inversely proportional relationship, i.e. the higher the score in Corsi's Test Backward and in Similarities (WISC) was, the lower the number of errors in oral calculation was (Table 9).

Regarding the time in oral calculation, no predictor turned out to be statistical significant, while as regards accuracy in written calculation, Expressive attention (the only measure excluded by EFA and CFA because of factorial loadings lower than .30) resulted a significant positive predictor $\left(\mathrm{t}(62)=2.21, \mathrm{p}<.05, \mathrm{n}^{2}=\right.$ .07); the higher the score in Expressive attention was, the higher the performance score in Written calculation was (Table 10).

Finally, the Attention factor turned out to be a significant regressor about Numerical knowledge by a directly proportional relationship (t $(62)=3.43, p<$ $\left..001, \eta^{2}=.16\right)$; the higher the score in Attention factor was in the participants, the higher the score in Numerical knowledge was (Table 11). 
Table 6: Multiple Regression Analysis with Errors in Reading as Dependent Variable, and Measures of Attention, of Working Memory and Intelligence Measures as Independent Variables

\begin{tabular}{|c|c|c|c|c|c|}
\hline Variable & B & SEB & $\mathbf{t}$ & $\mathbf{p}$ & $n^{2}$ \\
\hline (Intercept) & 19.35 & 5.00 & 3.87 & $<.001$ & .194 \\
\hline Expressive attention & .10 & .21 & .46 & n.s. & .003 \\
\hline Corsi's Test backward & -2.03 & 2.53 & -.80 & n.s. & .010 \\
\hline Cubes (WISC) & -.01 & .010 & -1.20 & n.s. & .023 \\
\hline Similarities (WISC) & -.69 & .20 & -3.52 & .001 & .166 \\
\hline
\end{tabular}

Table 7: Multiple Regression Analysis with Speed in Reading as Dependent Variable, and Measures of Attention, of Working Memory and Intelligence Measures as Independent Variables

\begin{tabular}{|c|c|c|c|c|c|}
\hline Variable & B & SEB & $\mathbf{t}$ & $\mathbf{p}$ & $n^{2}$ \\
\hline (Intercept) & .42 & .30 & 1.39 & n.s. & .030 \\
\hline Expressive attention & -.02 & .01 & -1.48 & n.s. & .034 \\
\hline Corsi's Test backward & .08 & .15 & .50 & n.s. & .004 \\
\hline Cubes (WISC) & .01 & .01 & .49 & n.s. & .004 \\
\hline Similarities (WISC) & .04 & .01 & 3.71 & .000 & .182 \\
\hline
\end{tabular}

Table 8: Multiple Regression Analysis with Speed Writing as Dependent Variable, and Measures of Attention, of Working Memory and Intelligence Measures as Independent Variables

\begin{tabular}{|c|c|c|c|c|c|}
\hline Variable & B & SEB & $\mathbf{t}$ & $\mathbf{p}$ & $n^{2}$ \\
\hline (Intercept) & 16.39 & 10.24 & 1.60 & n.s. & .040 \\
\hline Expressive attention & .10 & .43 & .24 & n.s. & .001 \\
\hline Corsi's Test backward & -.34 & 5.19 & -.07 & n.s. & .000 \\
\hline Similarities (WISC) & -.47 & .40 & -1.18 & n.s. & .022 \\
\hline
\end{tabular}

Table 9: Multiple Regression Analysis with Errors in Oral Calculation as Dependent Variable, and Measures of Attention, of Working Memory and Intelligence Measures as Independent Variables

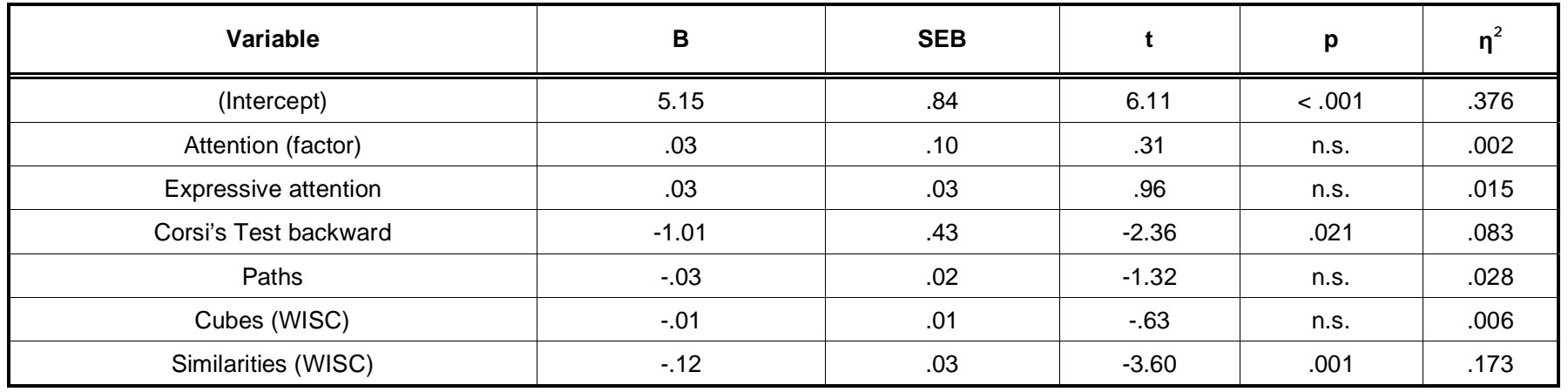


Table 10: Multiple Regression Analysis with Accuracy in Written Calculation as Dependent Variable, and Measures of Attention, of Working Memory and Intelligence Measures as Independent Variables

\begin{tabular}{|c|c|c|c|c|c|}
\hline Variable & B & SEB & $\mathbf{t}$ & $\mathbf{p}$ & $n^{2}$ \\
\hline (Intercept) & 2.79 & 1.22 & 2.29 & .025 & .078 \\
\hline Expressive attention & .11 & .05 & 2.21 & .031 & .073 \\
\hline Corsi's Test backward & -.46 & .62 & -.75 & n.s. & .009 \\
\hline Cubes (WISC) & .01 & .01 & 1.53 & n.s. & .036 \\
\hline Similarities (WISC) & -.05 & .05 & -1.14 & n.s. & .021 \\
\hline
\end{tabular}

Table 11: Multiple Regression Analysis with Numerical Knowledge as Dependent Variable, and Measures of Attention, of Working Memory and Intelligence Measures as Independent Variables

\begin{tabular}{|c|c|c|c|c|c|}
\hline Variable & B & SEB & $\mathbf{t}$ & p & $\eta^{2}$ \\
\hline (Intercept) & 1997.73 & 1176.10 & 1.70 & n.s. & .044 \\
\hline Expressive attention & -49.67 & 49.30 & -1.01 & n.s. & .016 \\
\hline Corsi's Test backward & 161.97 & 595.84 & .27 & n.s. & .001 \\
\hline Cubes (WISC) & 2.59 & 1.91 & 1.35 & n.s. & .029 \\
\hline Similarities (WISC) & -21.85 & 46.14 & -.47 & n.s. & .004 \\
\hline
\end{tabular}

\section{DISCUSSION}

\section{Correlation between Attention and Learning}

Through this study, we investigated the relationship between attention and learning in the first year of school. Based on the data, a relationship was found between efficiency of attentional processes and learning. Correctness and reading speed of a text are associated with the ability of visual selective attention. These data confirm a previous study [35]. The ability to recognise a target stimulus among other distractors is the parameter associated with reading performance in first grade. In fact, initially, children have to recognise the written signs and transform them into phonemic representations. This process requires children to analyse letter by letter (phonological recoding) and only after to recognise the word (spelling decoding). Both these modes of reading are based on the correspondence between perceptual stimuli and phonological processing; so the ability to pay attention to visual cues is important in the reading process. This type of visual selective attention is involved in execution of the Rapid Automatised Naming (RAN) task $[78,79]$, which is the most commonly measure used to predict reading. RAN is a task in which subjects are presented with arrays of high frequency items (letters, digits, colours or objects) and asked to name them as quickly as possible. Usually, children with reading difficulties perform this task accurately but slowly. In literature a strong relationship between visual selective attention measures and reading acquisition has been documented in a wide array of languages, with both inconsistent [80] and consistent [81] alphabetic orthographies.

In the early stages of the learning process of reading the alphabetic route is used and letters have to be precisely selected from irrelevant and cluttering letters by rapid orienting of visual attention before the correct letter-to-speech sound integration applies. Franceschini et al. [35] investigated whether prereading visual parietal-attention functioning may explain future reading emergence. Their results show that pre-reading attentional orienting, assessed by serial search performance and spatial cueing facilitation, captures future reading acquisition skills in grades 1 and 2. To obtain a correct integration of letter 
sound, the letters must be specifically selected through a rapid process of serial orientation. The orientation guides attentional integration allowing this learning to select the correct letter and correct the corresponding sound, simultaneously suppressing irrelevant ones. Our research is consistent with these findings and supports the evidence that in $1^{\text {st }}$ grade children's visuospatial attention is related to reading acquisition. Furthermore, it is important to emphasise that in the early stages of learning, phonological decoding is seen as partly overlapping a visual search task [33]. In fact, phonological decoding requires visuospatial segmentation of a string of letters into graphemes. Therefore, visuospatial attention is crucial in addition to phonological skills for correct reading.

The relationship between attention and spelling is not particularly highlighted in $1^{\text {st }}$ grade children. Probably the relationship between attention and spelling becomes more important after grade 2 . In the first two years of school, visuomotor coordination skills are dominant. Afterwards we can assume a sufficient level of automation in the process of writing. Our data are in agreement with the studies of Pinto et al. [82]. These studies highlighted the importance of the visual representation of the word in storage memory for its correct writing; in fact, writing errors correlate inversely with visuospatial active attention. Correctness in writing (homophone errors) seems to be associated with better ability to store the orthographic representation of a word and to direct attention to its recovery. There were no significant correlations with non-homophone errors, highlighting the different nature of the two types of error [82].

Speed of writing is associated with a greater efficiency of processes of visual selective attention, interference resistance and planning. It is interesting to note that the correlation is significant only with tests of visual attention that have graphic signs related to learning (numbers) and not with figures. The child has to learn new forms with specific characteristics and with different rules by design; in first grade of school a child overloads attentional resources to realise the graphical sign and this may affect spelling correctness. This finding might be due to the fact that, in order to be faster at writing, the child must have better planning and control of the interference of other graphic representations of letters.

Accuracy in oral calculation correlates with visuospatial working memory/active attentional system: we found associations between oral counting skills and measures of visuospatial attention, confirming a spatial representation of numerical knowledge $[83,84,85]$. Various sources of information demonstrate a link between visuospatial disabilities and numerical disabilities. This link has been attributed to the involvement of visuospatial working memory in numerical cognition.

Another datum that emerges from our study might be important. The rapidity in performing oral calculations (time) correlates with the ability of planning and inhibition. The data may suggest that children perform calculations faster when planning a strategy. For example, to resolve $21+35$, children have a visual representation of calculation in which they retain the tens in a buffer (e.g. add in memory 2 tens +3 tens $=5$ tens) and the units (e.g. 1 unit +5 units $=6$ units). Finally, the child recovers the information from the buffer and obtains the result (e.g. 5 tens and 6 units = 56). In fact, the link between performance in arithmetic and reflective strategy is emphasised by numerous studies $[86,87]$.

For written calculation a correlation emerges with the ability to control interference and inhibition. There are no correlations between written calculation and visual spatial skills. Probably the presence of a paper (the page with the calculations to be done) allows us not to overload the visuospatial skills: the attentional effort is lower because there is no need to retain the figures and the representation of the procedure in the working memory. Ability to control the interference consequently appears more important in solving this type of task.

Numerical knowledge correlates with the skills of visual selective attention, both in a number search task and in a symbol search task. So the role of visual skills in numerical knowledge is also emphasised by the correlation with a task where the stimulus is not numeric. We also point out that aspects of attentional planning are involved in numerical knowledge skills, as seen from the correlation with Matching numbers (in which planning and selective attention are involved). This indicates an association between numerical knowledge and a reflective and strategic approach to the task. This form of reflective thinking is usually labelled "metacognition". Reflection can facilitate the transfer of metacognitive strategy to new scholastic situations and it may be imagined as the bridge between knowledge and control [11].

Our results show that the correlation between attention and reading, writing and calculation is present 
in first grade children. A similar result was found in preschool children by Steele et al. [57]. They measured attentional performance in preschool children, with several tasks involving the capacity to sustain attention for a prolonged period of time (Go/No-Go task) to visually search for targets among distracters. Correlating attentional performance with maths and reading skills measured 1 year later, they found that sustained attention and visual search predict numeracy but not literacy.

\section{Attentional Factor Structure}

Our second objective was to identify a common factor in the development of various learnings that may be involved in the initial acquisition of reading, writing and mathematics during the first year of school. By factor analysis a single factor was identified using 4 paper and pencil tests. Analysing the characteristics of the tests included in the factor we identified the following common processes: visual attention, selection, maintaining the target in memory, monitoring information and processing speed (all the tests were timed). The factor is in part similar to the factor of visual selective/sustained attention detected by Steele et al. [57], but here there is also a time component. Hence the Factor was called "Rapid Visual Attention". Previous studies [58,3] reveal that with development, the attentional network specialises with a greater division between the factors. Attention processes, like other cognitive skills, may have a simpler factor structure earlier in childhood and become increasingly specialised with age, with sustained and selective attention being closely related in early childhood but further subdividing in later childhood [59,57]. Foundational components of attention, like inhibition, active attention, and shifting emerge during the first few years of life but continue to strengthen significantly throughout childhood and adolescence [88]. The factor consists of tests of attention and planning from the Cognitive Assessment System-CAS and we showed a close association between attention and attentional planning in children aged 6-7 years. This datum confirms some earlier research [89] which demonstrates that attention and planning are closely connected. In fact, planning, like other executive functions, develops over a long period of time until adolescence [90]. In our factor, attention is still closely linked to planning. So we could have found a type of initial planning, which has yet to specialise in line with maturation of brain circuits [90].

\section{Predictive Relationship between Attention and Learning}

With the third part of our study we support the hypothesis that effective initial learning might depend on proper functioning of the visual attentional system. Given the regression nature of our study, we assert a predictive role of Rapid Visual Attention Factor on acquisition of learning skills. In particular, we emphasize the importance of attentional factor and other attentional processes (that factor analysis excluded in the factor) on the development of reading, writing and calculation. The Rapid Visual Attention Factor contributes to rapidity in reading, speed in writing and numerical knowledge in first grade children, confirming the predictive role of visual attention on initial learning in this age group $[35,51]$.

Our study highlights that rapidity in recognising a target stimulus among other distractors has a predictive role on reading performance in first grade. This model indicates that the acquisition of reading ability starts from rapid analysis of visual elements. These data confirm the study on the role of the dimension of Processing Speed (PS) [25]. Some studies found that this ability is important already in preschoolers. In fact, the ability to identify and select information between distracters appears very important for the proper development of the ability to read from the time of preschool [35]. Later, during the first year of school, children's attentional skills are engaged in identifying and discriminating the shape of letters. Our data reveal that this type of attentional processes contributes to reading until the end of the first year of school. In fact, in this phase the children have not yet developed a faster type of reading which provides for access to mental lexicon. In this age group Rapid Visual Attention Factor has a predictive role on speed writing. These data confirm that the ability to have visual rapid attention is predictive of handwriting [39]. The importance of visual attention on writing processes are also confirmed by studies of children with attention disorders. These children have impaired performance in writing speed tests [44].

Regarding calculation, the data indicate that in the first class the Rapid Visual Attention Factor helps to explain the numerical knowledge [51]. This finding is consistent with the view that first grade schoolers use a mental model for calculation that requires rapid visuospatial attention.

In summary, the dimension of Rapid Visual Attention Factor involves PS and this is confirmed to be 
very important in early development of academic learning in normal development. Our study is consistent with recent data [25] that indicate a risk factor for multiple poor academic outcome in deficit of PS. Moreover, children with Dyslexia, Dyscalculia or ADHD also have deficits in PS [48]. Rapid Visual Attention Factor deficiency may be a common dimension to reading, writing and calculation and to related disorders. Because it is particularly important in the development of reading, writing and calculation, a deficit in Rapid Visual Attention Factor could impact on the ability of children to develop learning successfully. So, in educational and clinical contexts, it may be a useful to have early screening for Rapid Visual Attention Factor deficit. Our data may highlight which attentional aspect has to be strengthened to improve the academic outcomes of at-risk children and better understand the basis for overlap among reading, writing, calculation and attention skills. In this direction is interesting to note that, recently, some studies have shown that training in visual selective attention can determine improvements in academic learning [91].

Another datum that emerges from our results is that the role of visuospatial attention is also detectable in oral calculation. In particular, the Corsi's Test Backward (memory/visuospatial active attention) predicts accuracy in oral calculation. This datum shows that for children from the first grade oral calculation is a particularly complex task which involves largely visuospatial attentional processing. In fact, at this age mental calculation is not yet automated and the child does not use metacognitive strategies; to properly perform a task of this kind, children have to make recourse to complex operations of visualization, as already debated in the correlational discussion.

Finally, the Expressive Attention (inhibition ability and interference control) predict the accuracy in the written calculation. Children that in the first year of school have good written calculation skills are able to choose the relevant information and inhibit the irrelevant. This data emphasizes the predictive role of the use of metacognitive strategy on written calculation performance. In this direction some studies $[86,87]$ empathize the role of inhibition, interference control, planning and monitoring in calculation. All of these skills can be stimulated through metacognitive training. Metacognitive training was found to improve the mathematics achievement of normally-achieving students and to be related to improved math achievement in students with learning problems in mathematics.
There are limitations to the study. Attention and learning measures were taken simultaneously in first grade. It might be useful to take other variables in preschool children and then do a predictive study on these attentive abilities one year later, in first grade. It might be interesting to study the evolution of attentional factors in second and third grade, investigating the possible predictive role on learning. This is the future direction of our research.

\section{REFERENCES}

[1] Jaekel J, Wolke D, Bartman P. Poor attention rather than hyperactivity/impulsivity predicts academic achievement in very preterm and full-term adolescents. Psychol Med 2013; 43: 183-196. http://dx.doi.org/10.1017/S0033291712001031

[2] Loher S, Roebers CM. Executive Functions and Their Differential Contribution to Sustained Attention in 5- to 8Year-Old Children. J Edu Develop Psychol 2013; 3: 51-63. http://dx.doi.org/10.5539/jedp.v3n1p51

[3] Klenberg L, Korkman M, Lahti-Nuuttila P. Differential development of attention and executive functions in 3- to 12-yearold Finnish children. Dev Neuropsychol 2001; 20: 407-428. http://dx.doi.org/10.1207/S15326942DN2001 6

[4] Carlson SM, Moses LJ. Individual differences in inhibitory control and children's theory of mind. Child Dev 2001; 72: 1032-1053.

http://dx.doi.org/10.1111/1467-8624.00333

[5] Zelazo PD, Müller U, Frye D, Marcovitch S. The development of executive function. Monog Soc Res Child Dev 2003; 68: $11-27$.

http://dx.doi.org/10.1111/j.0037-976X.2003.00261.x

[6] Asato MR, Sweeney JA, Luna B. Cognitive processes in the development of TOL performance. Neuropsychol 2006; 44: 2259-2269.

http://dx.doi.org/10.1016/i.neuropsychologia.2006.05.010

[7] Pezzica S, Pinto G, Bigozzi L, Vezzani C. Where is my attention? Children's metaknowledge trough drawings, Educ Psychol 2015; 36: 616-637.

http://dx.doi.org/10.1080/01443410.2014.1003035

[8] Lagae L. Learning Disabilities: Definitions, Epidemiology, Diagnosis, and Intervention Strategies. Pediatr Clin N Am 2008; 55: 1259-1268.

http://dx.doi.org/10.1016/j.pcl.2008.08.001

[9] Froelich TE, Lanphear BP, Epstein JN, Barbaresi WJ, Katusic SK, Kahn RS. Prevalence, Recognition, and Treatment of Attention-Deficit/Hyperactivity Disorder in a National Sample of US Children. Arch Pediatic Adolesc Med 2007; 161: 857-64.

http://dx.doi.org/10.1001/archpedi.161.9.857

[10] Pezzica S, Tarchi C, Piccinelli F, Bigozzi L. Analisi quantitativa e di contenuto del percorso di Parent Training per genitori di bambini con ADHD: uno studio pilota. Psicologia Clinica dello Sviluppo 2013; 17: 45-72.

[11] Pezzica S, Bigozzi L. Un Parent Training Cognitivo Comportamentale e Mentalizzante per bambini con ADHD, Psicologia Clinica dello Sviluppo 2015; 12: 271-296.

[12] DuPaul GJ, Gormley MJ, Laracy SD. Comorbidity of LD and ADHD: implications of DSM-5 for assessment and treatment. J Learn Dis 2013; 46: 43-51.

http://dx.doi.org/10.1177/0022219412464351

[13] Mayes SD, Calhoun SL. Frequency of Reading, Math, and Writing Disabilities in Children with Clinical Disorders. Learn Individ Differ 2006; 16: 145-157.

http://dx.doi.org/10.1016/j.lindif.2005.07.004 
[14] Willcutt EG, Betjemann RS, McGrath LM et al., Etiology and neuropsychology of comorbidity between RD and ADHD: the case for multiple- deficit models. Cortex 2010; 46: 13451361.

http://dx.doi.org/10.1016/j.cortex.2010.06.009

[15] Fletcher JM, Shaywitz SE, Shaywitz BA. Comorbidity of learning and attention disorders. Separate but equal. Pediatr Clin North Am 1999; 46: 885-97.

http://dx.doi.org/10.1016/S0031-3955(05)70161-9

[16] Capano L, Minden D, Chen SX, Schacher RJ, Ickowicz A. Mathematical learning disorder in school-age children with attention-deficit hyperactivity disorder. Can J Psychiatry 2008; 53: 392-9.

[17] Miller AC, Fuchs D, Fuchs LS et al. Behavioral Attention: A Longitudinal Study of Whether and How It Influences the Development of Word Reading and Reading Comprehension among At-Risk Readers. J Res Educ Eff 2014; 7: 232-249. http://dx.doi.org/10.1080/19345747.2014.906691

[18] Alloway TP, Gathercole SE, Elliott J. Examining the link between working memory behaviour and academic attainment in children with ADHD. Dev Med Child Neurol 2010; 52: 632-6.

http://dx.doi.org/10.1111/j.1469-8749.2009.03603.x

[19] Rabiner D, Coie J. Early attention problems and children's reading achievement: A longitudinal investigation. J Am Acad Child Adolesc Psychiatry 2000; 39: 859-867.

http://dx.doi.org/10.1097/00004583-200007000-00014

[20] Martinussen R, Hayden J, Hogg-Johnson S, Tannock R. A meta-analysis of working memory impairments in children with attention-deficit/hyperactivity disorder. J Am Acad Child Adolesc Psychiatry 2005; 44: 377-84. http://dx.doi.org/10.1097/01.chi.0000153228.72591.73

[21] Marzocchi GM, Osterlaan J, Zuddas A, Cavolina P, Geurts H, Redigolo $D$ Contrasting deficits on executive functions between ADHD and reading disabled children. J Child Psychol Psychiatry 2008; 49; 543-552. http://dx.doi.org/10.1111/j.1469-7610.2007.01859.x

[22] DeJong PF, Van der Leij A. Specific contributions of phonological abilities to early reading acquisition: results from a Dutch latent variable longitudinal study. J Edu Psychol 1999; 91: 450-476.

http://dx.doi.org/10.1037/0022-0663.91.3.450

[23] Pingault JB, Tremblay RE, Vitaro F, et al. Childhood Trajectories of Inattention and Hyperactivity and Prediction of Educational Attainment in Early Adulthood: A 16-Year Longitudinal Population-Based Study. Am J Psychiatry 2010; 168: 1164-1170. http://dx.doi.org/10.1176/appi.ajp.2011.10121732

[24] Hart SA, Petrill SA, Willcutt E. Exploring how symptoms of attention-deficit/hyperactivity disorder are related to reading and mathematics performance: general genes, general environments. Psychol Sci 2010; 21: 1708-15. http://dx.doi.org/10.1177/0956797610386617

[25] Peterson RL, Boada R, McGrath LM, Willcutt EG, Olson RK, Pennington BF. Cognitive Prediction of Reading, Math, and Attention: Shared and Unique Influences. J Learn Disabil 2016; 49: 76-96.

http://dx.doi.org/10.1177/0022219415618500

[26] Pennington BF. From single to multiple deficit models of developmental disorders. Cognition 2006; 101: 385-413. http://dx.doi.org/10.1016/j.cognition.2006.04.008

[27] Kane MJ, Engle RW. The role of prefrontal cortex in workingmemory capacity, executive attention, and general fluid intelligence: an individual-differences perspective. Psychon Bul Rev 2002; 9; 637-71.

http://dx.doi.org/10.3758/BF03196323

[28] Hume LE, Allan DM, Lonigan CJ. Links between preschoolers' literacy interest, inattention, and emergent literacy skills. Learn Individ Differ 2016; 47: 88-95.

http://dx.doi.org/10.1016/j.lindif.2015.12.006
[29] Kennedy A, Radach R, Heller D, Pynte J. Reading as a perceptual process. Amsterdam: Elsevier Science 2000. http://dx.doi.org/10.1016/b978-008043642-5/50001-2

[30] Bosse ML, Valdois S. Influence of the visual attention span on child reading performance: A cross-sectional study. J Res Read 2009; 32: 230-253. http://dx.doi.org/10.1111/j.1467-9817.2008.01387.x

[31] Vidyasagar TR. Attentional gating in primary visual cortex: A physiological basis for dyslexia. Perception 2005; 34: 903911.

http://dx.doi.org/10.1068/p5332

[32] Vidyasagar TR, Pammer K. Dyslexia: A deficit in visualspatial attention, not in phonological processing. Trends Cogn Sci 2009; 14: 57-63.

http://dx.doi.org/10.1016/j.tics.2009.12.003

[33] Casco C, Tressoldi PE, Dell'Antonio A. Visual selective attention and reading efficiency are related in children. Cortex 1998; 34: 531-546. http://dx.doi.org/10.1016/S0010-9452(08)70512-4

[34] Ferretti G, Mazzotti S, Brizzolara D. Visual scanning and reading ability in normal and dyslexic children. Behav Neurol 2008; 19: 87-92.

http://dx.doi.org/10.1155/2008/564561

[35] Franceschini S, Gori S, Ruffino M, Pedrolli K, Facoetti A. A causal link between visual spatial attention and reading acquisition. Current Neurology 2012; 22: 814-819. http://dx.doi.org/10.1016/i.cub.2012.03.013

[36] Friedmann N, Dotan D, Rahamim E. Is the visual analyzer orthographic-specific? Reading words and numbers in letter position dyslexia. Cortex 2010; 46: 982-1004. http://dx.doi.org/10.1016/j.cortex.2009.08.007

[37] Pinto G, Bigozzi L, Tarchi C, Gamannossi Accorti B, Canneti. Cross-Lag Analysis of Longitudinal Associations between Primary School Students' Writing and Reading Skills Read Writ 2015; 28: 1233-1255. http://dx.doi.org/10.1007/s11145-015-9569-9

[38] Cossu G, Gugliotta M, Marshall JC. Acquisition of reading and written spelling in a transparent orthography: Two nonparallel processes'? Read Writ 1995; 7: 9-22.

http://dx.doi.org/10.1007/BF01026945

[39] Amundson SJ, Weil M. Prewriting and handwriting skills. In J. Case-Smith (Ed.) Occupational therapy for children (4th ed.) St. Louis, MO: Mosby 2001.

[40] Seymour PHK, Macgregor CJ. Developmental Dyslexia: A Cognitive Developmental Analysis Of Phonological Morphemic And Visual Impairments. Cogn Neuropsychol 1984; 1: 43-82. http://dx.doi.org/10.1080/02643298408252016

[41] Cornoldi C, Del Prete F, Gallani A, Sella F, Re AM. Components affecting expressive writing in typical and disabled writers. In: Scruggs TE, Mastropieri MA (eds) Literacy and Learning. Advances in learning and behavioral disabilities. Bingley, UK: Emerald Group 2003; 3: 269-286.

[42] Olive T. Working memory in writing: Empirical evidence from the dual-task technique. Eur Psychol 2004: 9: 32-42. http://dx.doi.org/10.1027/1016-9040.9.1.32

[43] Mayes SD Calhoun SL, Crowell EW. Learning Disabilities and ADHD Overlapping Spectrum Disorders J Learn Disabil 2000; 33: 417-424.

[44] Noda W, Ito $\mathrm{H}$, Fujita $\mathrm{C}$, et al. Examining the relationships between attention deficit/hyperactivity disorder and developmental coordination disorder symptoms, and writing performance in Japanese second grade students. Res Dev Disabil 2013; 34: 2909-16. http://dx.doi.org/10.1016/j.ridd.2013.05.023

[45] Tsai LH, Meng LF, Hung LY, Chen HY, Lu CP. Coincidence of homophone spelling errors and attention problems in 
school children: A survey study. Res Dev Disabil 2011; 32: 75-80.

http://dx.doi.org/10.1016/..ridd.2010.08.014

[46] Re AM, Mirandola C, Esposito SS, Capodieci A. Spelling errors among children with ADHD symptoms: the role of working memory. Res Dev Disabil 2014; 35: 2199-204. http://dx.doi.org/10.1016/j.ridd.2014.05.010

[47] Rodriguez A, Jarvelin MR, Obel C, et al. Do inattention and hyperactivity symptoms equal scholastic impairment? Evidence from three European cohorts. BMC Public Health 2007; 7: 327.

http://dx.doi.org/10.1186/1471-2458-7-327

[48] Moll K, Göbel SM, Gooch D, Landerl K, Snowling MJ. Cognitive Risk Factors for Specific Learning Disorder: Processing Speed, Temporal Processing, and Working Memory. J Learn Disabil 2016; 49: 272-81. http://dx.doi.org/10.1177/0022219414547221

[49] Ramussen C, Bisanz J. Representation and working memory in early arithmetic. J Exp Child Psychol 2005; 91: 137-157. http://dx.doi.org/10.1016/j.jecp.2005.01.004

[50] Bull R, Espy KA, Wiebe SA. Short-term memory, working memory, and executive functioning in preschoolers: Longitudinal predictors of mathematical achievement at 7 years. Dev Neuropsychol 2008; 33: 205-228. http://dx.doi.org/10.1080/87565640801982312

[51] Anobile G, Stievano P, Burr DC. Visual sustained attention and numerosity sensitivity correlate with math achievement in children. J Exp Child Psychol 2013; 116: 380-391. http://dx.doi.org/10.1016/i.jecp.2013.06.006

[52] Wei W, Chen C, Zhou X. Spatial Ability Explains the Male Advantage in Approximate Arithmetic. Front Psychol 2016; 7: 306 http://dx.doi.org/10.3389/fpsyg.2016.00306

[53] Dehaene S, Piazza M, Pinel P, Cohen L. Three parietal circuits for number processing. Cogn Neuropsychol 2003; 20: 487-506.

http://dx.doi.org/10.1080/02643290244000239

[54] De Smedt B, Janssen R, Bouwens K, Verschaffel L, Boets B, Ghesquiere $P$. Working memory and individual differences in mathematics achievement: A longitudinal study from first grade to second grade. J Exp Child Psychol 2009; 103: 189201. http://dx.doi.org/10.1016/j.jecp.2009.01.004

[55] Bull R , Scerif G. Executive functioning as a predictor of children's mathematics ability: Inhibition, switching, and working memory. Dev Neuropsychol 2001; 19: 273-293. http://dx.doi.org/10.1207/S15326942DN1903 3

[56] Bull R , Johnston RS, Roy JA (1999) Exploring the roles of the visual-spatial sketch pad and central executive in children's arithmetical skills: Views from cognition and developmental neuropsychology. Dev Neuropsychol 1999; 15: 421-442.

http://dx.doi.org/10.1080/87565649909540759

[57] Steele A, Karmiloff-Smith A, Cornish K, Scerif G. The Multiple Subfunctions of Attention: Differential Developmental Gateways to Literacy and Numeracy. Child Dev 2012; 83: 2028-2041.

http://dx.doi.org/10.1111/j.1467-8624.2012.01809.x

[58] Manly T, Anderson V, Nimmo-Smith I, Turner A, Watson P, Robertson IH. The differential assessment of children's attention: the Test of Everyday Attention for Children (TEACh), normative sample and ADHD performance. J Child Psychol Psychiatry 2001; 42: 1065-81.

http://dx.doi.org/10.1111/1469-7610.00806

[59] Breckenridge K, Braddick O, Atkinson, J. The organization of attention in typical development: a new preschool attention test battery. Br J Dev Psychol. 2013; 31: 271-88.

http://dx.doi.org/10.1111/bjdp.12004
[60] WMA [homepage on internet]. Fortaleza 2016 World Medical Association, Inc. [updated 2016 May 1; cited 2016 May 19] (2013). Declaration of Helsinki: Ethical Principles for Medical Research Involving Human Subjects.. Retrieved from http: //www.wma.net/en/30publications/10policies/b3/index.html

[61] Cornoldi C, Colpo G, Gruppo MT. Prove di Lettura MT per la Scuola elementare. Firenze: Organizzazioni Speciali 1998.

[62] Tressoldi PE, Cornoldi C, Batteria per la valutazione della scrittura e della competenza ortografica per la scuola dell'obbligo. Firenze: Giunti OS 2008.

[63] Pinto G, Bigozzi L, Gamannossi BA, Vezzani C. Emergent literacy and early writing skills. J Genet Psychol 2012; 173; 330-354. http://dx.doi.org/10.1080/00221325.2011.609848

[64] Bigozzi L, Tarchi C, Caudek C, Pinto G. Predicting reading and spelling disorders: a 4-year prospective cohort study. Front. Psychol 2016; 7: 337. http://dx.doi.org/10.3389/fpsyg.2016.00337

[65] Bigozzi L, Tarchi C, Pinto G. Consistency and stability of Italian children's spelling in dictation versus composition assessments. Reading\& Writing Quarterly in press. http://dx.doi.org/10.1080/10573569.2015.1102111

[66] Tressoldi PE, Cornoldi C. Batteria per la valutazione della scrittura e della competenza ortografica nella scuola dell'obbligo. Firenze: Organizzazioni Speciali 2000.

[67] Cornoldi C, Lucangeli D, Bellina M. AC-MT 6-11. Test di autovalutazione delle abilità di calcolo e soluzione di problemi. Gruppo MT. Trento: Erickson 2002.

[68] Naglieri JA, Das JP. Cognitive Assessment System Interpretive Handbook. Chicago: Riverside Publishing Company 1997.

[69] Lanfranchi S, Vianello R. Caratteristiche della memoria di lavoro in bambini dai 4 ai 6 anni. Giornale italiano di psicologia 2009; 3: 613-634.

[70] Corsi PM. Human memory and the medial temporal region of the brain. (Unpublished doctoral dissertation) Montreal: McGill University 1972.

[71] Mammarella IC, Toso C, Pazzaglia F, Cornoldi C. BVS-Corsi: Batteria per la valutazione della memoria visiva e spaziale [BVS-Corsi: A test battery for assessing visual and spatial memory]. Trento: Erickson 2008.

[72] Wechsler D. Wechsler Intelligence Scale for Children-4th Edition (WISC-IV®) San Antonio, TX: Harcourt Assessment 2003.

[73] Orsini A, Picone L. WISC-III Contributo alla taratura italiana. Firenze: Organizzazioni Speciali 2006.

[74] Sattler JM, Dumont R. Assessment of Children: WISC-IV and WPPSI-III Supplement. San Diego, CA: Jerome M. Sattler, 2004.

[75] Bentler PM. Comparative fit Index in structural models. Psychol Bul 1990; 107: 238-246. http://dx.doi.org/10.1037/0033-2909.107.2.238

[76] Bagozzi RP, Baumgartner $\mathrm{H}$. The evaluation of structural equation models an hypothesis testing. In: Bagozzi RP (ed.), Principles of marketing research. Oxford: Blackwell 1994. 386-423.

[77] Hu LT, Bentler P. Cutoff criteria for fit indexes in covariance structure analysis: Conventional criteria versus new alternatives. Struct Equ Modeling 1999; 6: 1-55. http://dx.doi.org/10.1080/10705519909540118

[78] Wolf M, Bowers PG. The double-deficit hypothesis for the developmental dyslexia. J. Educ Psychol 1999: 91: 415-438. http://dx.doi.org/10.1037/0022-0663.91.3.415

[79] Kirby J, Georgiou G, Martinussen R, Parrilla R. Naming speed and reading: from prediction to instruction. Read Res Q 2010; 45: 341-362. http://dx.doi.org/10.1598/RRQ.45.3.4 
[80] Plaza M, Cohen $\mathrm{H}$. The interaction between phonological processing, syntactic awareness and naming speed in the reading and spelling performance of first grade children. Brain Cogn 2003; 53: 287-292.

http://dx.doi.org/10.1016/S0278-2626(03)00128-3

[81] Di Filippo G, Brizzolara D, Chilosi A, et al. Rapid naming, not cancellation speed or articulation rate, predicts reading in an orthographically regular language (Italian). Child Neuropsychol 2005; 11: 349-361. http://dx.doi.org/10.1080/09297040490916947

[82] Pinto G, Tarchi C, Bigozzi L. The relationship between oral and written narratives: A three-year longitudinal study of narrative cohesion, coherence, and structure. British Journal of Educational Psychology 2015; 85, 551-569. http://dx.doi.org/10.1111/bjep.12091

[83] Dehaene S. Varieties of numerical abilities. Cognition 1992; 44: 1-42. http://dx.doi.org/10.1016/0010-0277(92)90049-N

[84] Von Aster M, Shalev R. Number development and developmental dyscalculia. Dev Med Child Neurol 2007; 49: 868-873.

http://dx.doi.org/10.1111/j.1469-8749.2007.00868.x

[85] Praet M, Titeca D, Ceulemans A, Desoete A. Number Sense in Siblings of Children with Mathematical Learning Disabilities: A Longitudinal Study. Intellect Disabl Diagn J 2013; 1: 67-73.
[86] Lucangeli D, Cornoldi C, Tellarini M, Scruggs TE, Mastropieri MA. Metacognition and learning disabilities in mathematics. Advances in learning and behavioral disabilities 1998; 12: 219-244.

[87] Ozsoy G. An investigation of the relationship between metacognition and mathematics achievement. Asia Pac Educ Rev 2011; 2: 227-235. http://dx.doi.org/10.1007/s12564-010-9129-6

[88] Zelazo P, Carlson SM. Hot and cool executive function in childhood and adolescence: development and plasticity. Child Dev Perspect 2012; 6: 354-360. http://dx.doi.org/10.1111/j.1750-8606.2012.00246.x

[89] Kranzler $\mathrm{JH}$, Weng LJ. Factor Structure of the PASS Cognitive Tasks: A Reexamination of Naglieri JA. et al. 1991. J Sch Psychol 1995; 33: 143-157. http://dx.doi.org/10.1016/0022-4405(95)00004-6

[90] Selemon LD. A role for synaptic plasticity in the adolescent development of executive function. Transl Psychiatry 2013; 5: e328. http://dx.doi.org/10.1038/tp.2013.7

[91] Shalev L, Tsal Y, Mevorach C. Computerized Progressive Attentional Training (CPAT) Program: Effective Direct Intervention for Children with ADHD Child Neuropsychol 2007; 13: 382-388. http://dx.doi.org/10.1080/09297040600770787

DOI: http://dx.doi.org/10.6000/2292-2598.2016.04.02.3

(c) 2016 Bigozzi et al.; Licensee Lifescience Global.

This is an open access article licensed under the terms of the Creative Commons Attribution Non-Commercial License (http://creativecommons.org/licenses/by-nc/3.0/) which permits unrestricted, non-commercial use, distribution and reproduction in any medium, provided the work is properly cited. 